Article

\title{
Superhard Boron-Rich Boron Carbide with Controlled Degree of Crystallinity
}

\author{
Kallol Chakrabarty®, Wei-Chih Chen, Paul A. Baker®, Vineeth M. Vijayan $\mathbb{D}^{\circledR}$, \\ Cheng-Chien Chen $(\mathbb{D}$ and Shane A. Catledge * \\ Department of Physics, University of Alabama at Birmingham, Birmingham, AL 35294, USA; \\ kallol89@uab.edu (K.C.); weichih@uab.edu (W.-C.C.); pabaker@uab.edu (P.A.B.); vineeth@uab.edu (V.M.V.); \\ chencc@uab.edu (C.-C.C.) \\ * Correspondence: catledge@uab.edu
}

Received: 8 July 2020; Accepted: 13 August 2020; Published: 16 August 2020

\begin{abstract}
Superhard boron-rich boron carbide coatings were deposited on silicon substrates by microwave plasma chemical vapor deposition (MPCVD) under controlled conditions, which led to either a disordered or crystalline structure, as measured by X-ray diffraction. The control of either disordered or crystalline structures was achieved solely by the choice of the sample being placed either directly on top of the sample holder or within an inset of the sample holder, respectively. The carbon content in the B-C bonded disordered and crystalline coatings was 6.1 at. $\%$ and 4.5 at. $\%$, respectively, as measured by $\mathrm{X}$-ray photoelectron spectroscopy. X-ray diffraction analysis of the crystalline coating provided a good match with a $\mathrm{B}_{50} \mathrm{C}_{2}$-type structure in which two carbon atoms replaced boron in the $\alpha$-tetragonal $B_{52}$ structure, or in which the carbon atoms occupied different interstitial sites. Density functional theory predictions were used to evaluate the dynamical stability of the potential $\mathrm{B}_{50} \mathrm{C}_{2}$ structural forms and were consistent with the measurements. The measured nanoindentation hardness of the coatings was as high as $64 \mathrm{GPa}$, well above the $40 \mathrm{GPa}$ threshold for superhardness.
\end{abstract}

Keywords: ceramics/coating materials; chemical synthesis; vapor deposition; mechanical properties; crystal structure; computer simulation

\section{Introduction}

Materials based on the light elements of carbon, nitrogen, oxygen, and boron with strong covalent bonds comprise some of the hardest known materials [1-3]. These light elements can form short bond lengths with each other and are inclined to form directional covalent bonds, making the structures they form difficult to compress or distort. Boron carbide is the third hardest material after diamond and cubic boron nitride. Elemental boron can form base structures consisting of $\mathrm{B}_{12}$ icosahedra, $\mathrm{B}_{6}$ octahedra, linear atomic chains, and/or atomic clusters in a three-dimensional network [4-7]. There are multiple possible arrangements of icosahedra, together with additional structural elements, that can form during material processing routes $[3,8,9]$. The common stoichiometry of boron carbide includes $B_{13} C_{2}, B_{12} C_{3}$, and $B_{4} C$, as well as some structures that are similar to $B_{12} C_{3}[3,8]$. Some notable boron carbide crystal structures are tetragonal, including $B_{50} C_{2}, B_{50} C, B_{48} C_{3}, B_{51} C$, and $B_{49} C_{3}[9,10]$. Several theoretical and experimental studies have suggested that, as the boron to carbon ratio varies, the atomic bonding, electron density, mechanical properties, and lattice constants of boron carbide change significantly [11-15]. Thermodynamically, the most stable forms of boron carbide are the $\alpha$-tetragonal and rhombohedral crystal structures [11,16]. Boron-rich carbides are most known for their high hardness, extreme abrasion resistance, high melting point, thermal stability, high mechanical strength, high neutron absorption, and their ability to function in extreme conditions of pressure, 
temperature, and corrosive environments [11,16-21]. These properties make boron carbide suitable in refractory applications, medical applications, fast breeders, lightweight armors, ballistic armors, as cutting tools, as an abrasive powder, and for high-temperature thermoelectric conversion. Depending on the growth process, a wide range of boron carbide stoichiometries can be created with desirable chemical and electrical properties, opening the door to other potential applications.

Several techniques and experimental conditions have been used to synthesize boron carbides using a variety of boron precursors [22,23]. The preparation of novel boron-rich boron carbide was reported from high-pressure high-temperature (HPTP) cells which yield very small volumes of material [22]. These methods are not scalable for producing coatings for large areas and it can be difficult to control impurities. Instead, chemical vapor deposition (CVD) has proven to be a scalable technology for synthesizing a wide range of coating materials including boron carbide with large area uniformity [23,24]. A primary challenge of CVD is to find the optimum conditions that are favorable for the growth of the desired phase.

The objective of this work is to investigate deposition conditions leading to superhard boron-rich boron carbide coatings, to evaluate their structure experimentally and by density functional theory, and to demonstrate control of boron carbide crystallinity by the appropriate choice of sample height in the plasma. To this end, superhard boron-rich boron carbide coatings were synthesized by microwave plasma chemical vapor deposition (MPCVD), using conditions of chamber pressure and microwave power that we found led to copious amounts of atomic boron plasma emission [9,25]. Reactant gases for the growth of the boron carbide coatings include $\mathrm{H}_{2}$ and $\mathrm{B}_{2} \mathrm{H}_{6}$, but little is known of the plasma species and underlying the spectroscopic aspects responsible for boron carbide growth in its various structural forms. Investigation of the excited state plasma species from optical emission spectroscopy in our MPCVD system shows that emission from atomic boron is highest at low chamber pressure and high microwave power $[25,26]$. Copious amounts of atomic boron in the plasma may be beneficial under some growth conditions for producing high hardness boron-rich carbides, such as $\mathrm{B}_{50} \mathrm{C}_{2}, \mathrm{~B}_{50} \mathrm{C}$, $\mathrm{B}_{48} \mathrm{C}_{3}, \mathrm{~B}_{51} \mathrm{C}, \mathrm{B}_{49} \mathrm{C}_{3}$, or many other forms of boron-rich carbide. The enhanced atomic boron emission in the plasma with the MPCVD conditions used in the current study yielded a higher boron content in the boron carbide coatings with measured superhardness (i.e., hardness greater than $40 \mathrm{GPa}$ ). In addition, we report that with very modest changes in the sample stage design (and thus the proximity of the sample to the plasma), the degree of crystallinity in the coating could vary significantly.

\section{Materials and Methods}

\subsection{MPCVD Process}

Boron carbide coatings were grown in a microwave plasma chemical vapor deposition (MPCVD) system, as shown in Figure 1 (Wavemat Inc. Plymouth, MI, USA). The sample surface was heated by direct contact with the plasma. Both the sample stage and outer resonance cavity jacket were water cooled. A quartz bell jar isolates the low-pressure plasma environment from the resonance cavity. N-type (100)-oriented silicon substrates with $525 \mu \mathrm{m}$ thickness were placed on the surface of a $0.5^{\prime \prime}$ diameter molybdenum screw placed along the central axis of the bell jar. Sample substrates were cleaned in acetone, methanol, and distilled water. The microwave power was $1 \mathrm{~kW}$ and the chamber pressure was 15 Torr. Hydrogen $\left(\mathrm{H}_{2}\right)$ was used as the carrier gas and a diborane mixture $\left(90 \% \mathrm{H}_{2}, 10 \% \mathrm{~B}_{2} \mathrm{H}_{6}\right.$, and ppm carbon) as the reactive gas. Low levels of residual carbon have been found to appear consistently in high-boron deposited films. The gas flow rates were: 500 standard cubic centimeters per minute (SCCM) of hydrogen and 1 SCCM of the diborane mixture. Two types of samples were grown at an average substrate temperature of $825^{\circ} \mathrm{C}$ with the same experimental conditions, with the exception of how the silicon substrate was positioned in/on a flat molybdenum screw, as shown in Figure 1. For samples designated as BC-1, the silicon substrate rested on the flat surface of the molybdenum screw, whereas for samples designated as BC-2, the silicon substrate rested 
within a $0.5 \mathrm{~mm}$ inset of the screw face such that the substrate was flush with the surrounding Mo surface. BC-1 and BC-2 samples were grown at the same average temperature of $825 \pm 25^{\circ} \mathrm{C}$.

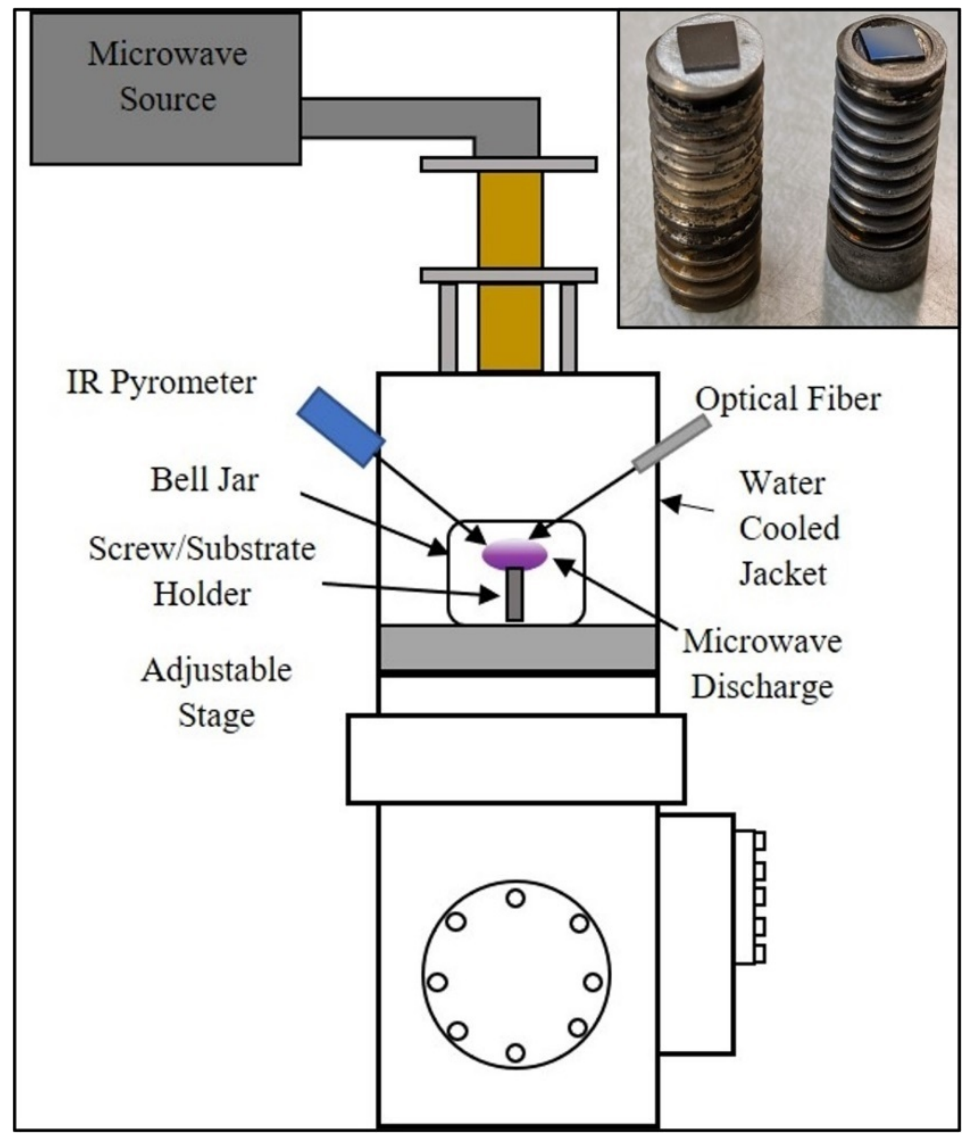

Figure 1. Schematic of the $6 \mathrm{~kW}$ Microwave Plasma Chemical Vapor Deposition (MPCVD) chamber showing plasma confined within a quartz bell jar. The inset shows how the substrates were placed on the substrate holder for sample BC-1 (flat screw) and BC-2 (screw with inset).

\subsection{Characterization Techniques}

Samples were characterized using X-ray photoelectron spectroscopy (XPS), glancing angle X-ray diffraction (XRD), Raman spectroscopy, Fourier transform infrared spectroscopy (FTIR), nanoindentation, and scanning electron microscopy (SEM). The XPS instrumentation was a Phi Electronics Versaprobe 5000 (Phi Electronics, Chanhassen, MN, USA), equipped with a micro-focused Al monochromatic source $(\lambda=1486.6 \mathrm{eV})$ and a dual anode conventional X-ray source with a neutralizer. Survey spectra were taken with an incident energy of $1253.6 \mathrm{eV}$ and both sources were used for data collection. The XRD pattern was obtained by a Panalytical Empyrean X-ray diffractometer (Copper $\mathrm{K}_{\alpha 1}, \lambda=1.54059 \AA$ A) (Malvern, Panalytical, Almelo, Nederland). XRD patterns were acquired using a glancing angle 2-theta scan with an angle of incidence of 1 degree. The diffraction optics included a hybrid monochromator with a $1 / 8^{\circ}$ divergence slit and a $1 / 16^{\circ}$ anti-scattering slit and a parallel plate collimator on the diffracted beam path with a proportional detector. HighScore Plus software (version 4.8) was used to analyze phase structure. Rietveld refinement was used to find the lattice constants of the BC-2 sample. Raman spectra were collected with a micro-Raman spectrometer (Dilor XY, Lille, France) with a $532 \mathrm{~nm}$ laser, 1200 groove/mm grating, and a 100× microscope objective. The Bruker alpha FTIR spectrometer (Bruker Corporation, Billerica, MA, USA) with attenuated total reflectance (ATR) mode was used to acquire Fourier transform infrared spectra (ranging from 4000 to $500 \mathrm{~cm}^{-1}$ ). The total number of scans used to record the FTIR spectra was 1024 with $4 \mathrm{~cm}^{-1}$ resolution. SEM images were taken using a FEI QuantaTM 650 FEG scanning electron microscope 
(Thermo Fisher Scientific, Hillsboro, OR, USA) at $20 \mathrm{kV}$ beam voltage. Hardness was measured using an MTS NanoIndenter XP with a Berkovich diamond tip (nominal radius $50 \mathrm{~nm}$ ). The calibration of the indenter area function before and after hardness measurements was tested for the fused silica standard (accepted Young's modulus of $72 \mathrm{GPa}$ ) to confirm that the tip geometry did not change during the testing of all samples. All indents, including those on silica, were made to a maximum depth of $150 \mathrm{~nm}$. The measured hardness was determined at maximum load. The range of measured silica before/after Young's modulus values was found to be consistent with the accepted value, and therefore the indenter tip area function was determined not to have changed significantly during actual sample testing.

\subsection{Density Functional Theory}

Density function theory (DFT) $[27,28]$ calculations were performed with the Vienna ab initio simulation package (VASP) version 5.4.4 [29,30], using plane-wave basis sets and the pseudopotential method. The projector augmented wave (PAW) method [31,32] and Perdew-Burke-Ernzerhof generalized gradient approximation (GGA) functional [33] were chosen to conduct the DFT calculations. The wavefunctions were expended with a kinetic energy cutoff of $600 \mathrm{eV}$. A $\Gamma$-centered $10 \times 10 \times$ 6 Monkhorst-Pack grid [34] was used in the Brillouin zone sampling. In the structural relaxation, all structures were relaxed until the force on each atom was less than $10^{-3} \mathrm{eV} / \AA$. The convergence criterion of the electronic loop was set to be $10^{-6} \mathrm{eV} /$ unit cell. The phonon calculations were performed using the VASP and PHONOPY [35] packages. The force constants were obtained by density functional perturbation theory implemented in VASP. By Fourier transforming the force constants, PHONOPY can construct the dynamical matrix at an arbitrary q-vector. The phonon dispersion in turn can be calculated by diagonalizing the dynamical matrices. For mechanical properties, the elastic constants were computed directly by VASP. The bulk and shear moduli were then derived by the Voigt-Reuss-Hill averaging method. The theoretical Vickers hardness was then calculated by Chen's model [36]. The structural visualization and XRD patterns were obtained by VESTA software version 3.4 .3 [37].

\section{Results}

\subsection{X-ray Photoelectron Spectroscopy}

The XPS of the BC-1 sample showed that the surface is composed of $88.1 \% \mathrm{~B}, 8.7 \% \mathrm{C}$, and $3.2 \% \mathrm{O}$ (rel. at\%) with no other elements present. A small amount of surface contamination due to adventitious carbon is generally present in samples that have been exposed to air. The complete peak assignments with binding energy is given in Table 1 . The high-resolution B1s scan in Figure $2 \mathrm{~b}$ shows that $75 \%$ of the boron is B-C bonded and the remaining 25\% is B-B bonded [38,39]. The high-resolution C1s scan in Figure $2 \mathrm{c}$ shows that $9 \%$ of the carbon is $\mathrm{C}-\mathrm{O}$ bonded and the high-resolution $\mathrm{O} 1 \mathrm{~s}$ scan also shows $\mathrm{C}-\mathrm{O}$ bonding in Figure 2d [40,41]. Figure 2c also shows that $22 \%$ of the carbon is C-C bonded and the remaining $69 \%$ is B-C bonded [38,39]. Using this information, our XPS measured carbon content in the B-C bonded BC-1 sample is $6 \%$. The XPS of the BC-2 sample shows that the surface is composed of $81.0 \% \mathrm{~B}, 12.6 \% \mathrm{C}, 4.4 \% \mathrm{O}$, and $2.0 \% \mathrm{~N}$ (rel. at \%). The complete peak assignments with binding energy is given in Table 1. The high-resolution B1s scan in Figure 3b shows that 39\% of the boron is $\mathrm{B}-\mathrm{C}$ bonded, $48 \%$ of the boron is $\mathrm{B}-\mathrm{B}$ bonded, $10 \%$ of the boron is $\mathrm{B}-\mathrm{N}$ bonded, and the remaining $3 \%$ of the boron is B-O bonded [38,39]. Corresponding peak deconvolution for O1s and N1s reveals B-O and B-N bonding in Figure 3d,e, respectively. [42]. The high-resolution $\mathrm{C} 1 \mathrm{~s}$ scan in Figure 3c shows that $26 \%$ of the carbon is $\mathrm{C}-\mathrm{O}$ bonded and the high-resolution O1s scan also confirms C-O bonding in Figure 3d [40,41]. According to the high-resolution C1s scan of the BC-2 sample in Figure 3c, 38\% of the carbon is C-C bonded and the remaining $36 \%$ is $B-C$ bonded [38,39]. Using this information, our XPS measured carbon content in the $\mathrm{B}-\mathrm{C}$ bonded $\mathrm{BC}-2$ sample is $4.5 \%$. The stoichiometric ratio for $\mathrm{B}_{50} \mathrm{C}_{2}$ should be $96 \%$ B, $4 \%$ C, and the estimated carbon content in the part of the sample that contains B-C bonding is $4.5 \%$, which is close to the $4 \%$ expected. 
Table 1. X-ray photoelectron spectroscopy compositional analysis and fitted parameters of B1s, C1s, O1s, and N1s of BC-1 and BC-2 samples. "Data from reference [38-43]."

\begin{tabular}{ccccc}
\hline Sample & Peaks & Binding Energy & Peak Area (\%) & Assignment \\
\hline \multirow{5}{*}{ BC-1 } & B1s & 186.2 & 75 & B-C \\
& B1s & 187.4 & 25 & B-B \\
& C1s & 283.3 & 69 & C-B \\
& C1s & 284.9 & 22 & C-C \\
& C1s & 286.5 & 9 & C-O \\
O1s & 533.3 & 100 & C-O \\
\hline \multirow{5}{*}{ BC-2 } & B1s & 187.0 & 39 & B-C \\
& B1s & 188.5 & 48 & B-B \\
& B1s & 190.5 & 10 & B-N \\
& B1s & 192.0 & 3 & C-B \\
& C1s & 282.0 & 26 & C-C \\
& C1s & 284.5 & 36 & C-O \\
& C1s & 287.0 & 38 & C-O \\
& O1s & 532.3 & 90 & B-O \\
\hline
\end{tabular}
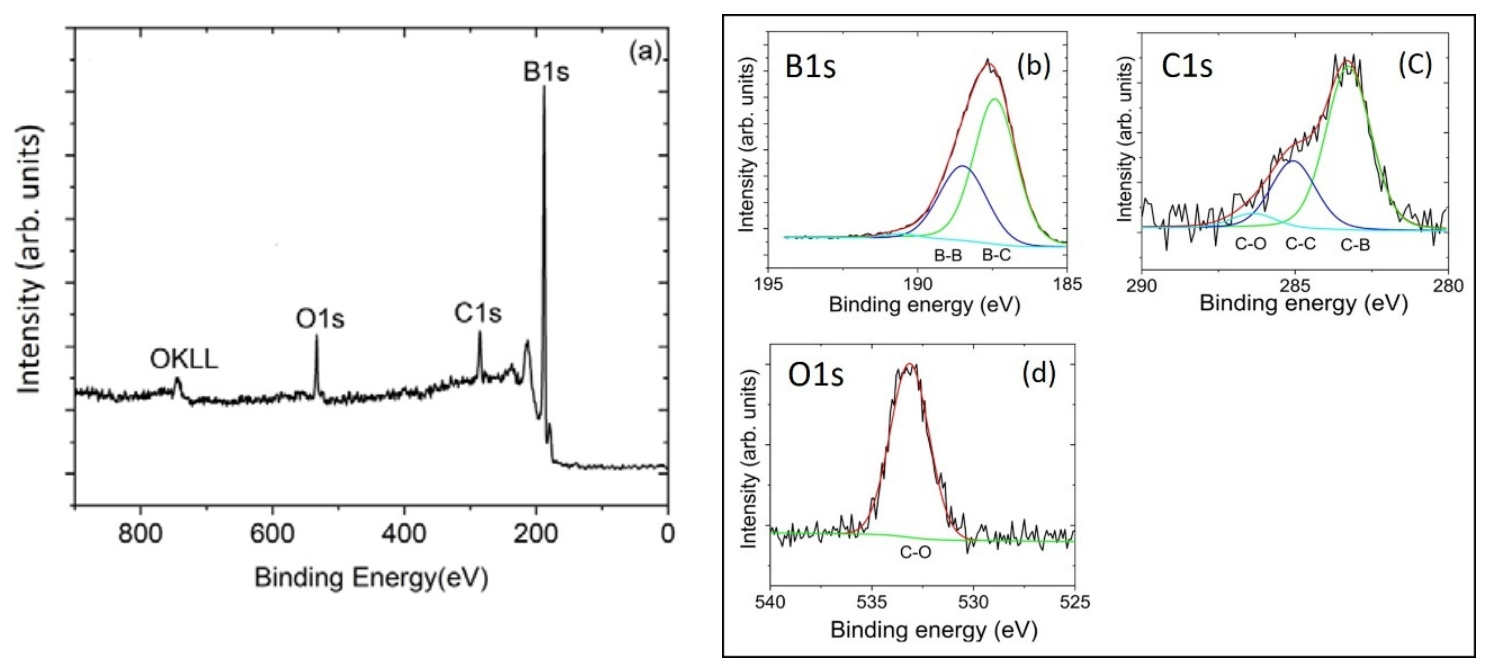

Figure 2. X-ray photoelectron spectroscopy survey scans of (a) the BC-1 coating with an elemental composition of $88.1 \%$ B, 8.7\% C, and 3.2\% O. Panels (b-d) show high-resolution scans for B1s, C1s, and $\mathrm{O} 1 \mathrm{~s}$, respectively, with corresponding peaks assigned to B-C, B-B, and C-C (adventitious carbon) bonding. Sample BC-1 also shows bonding associated with $\mathrm{C}-\mathrm{O}$. 

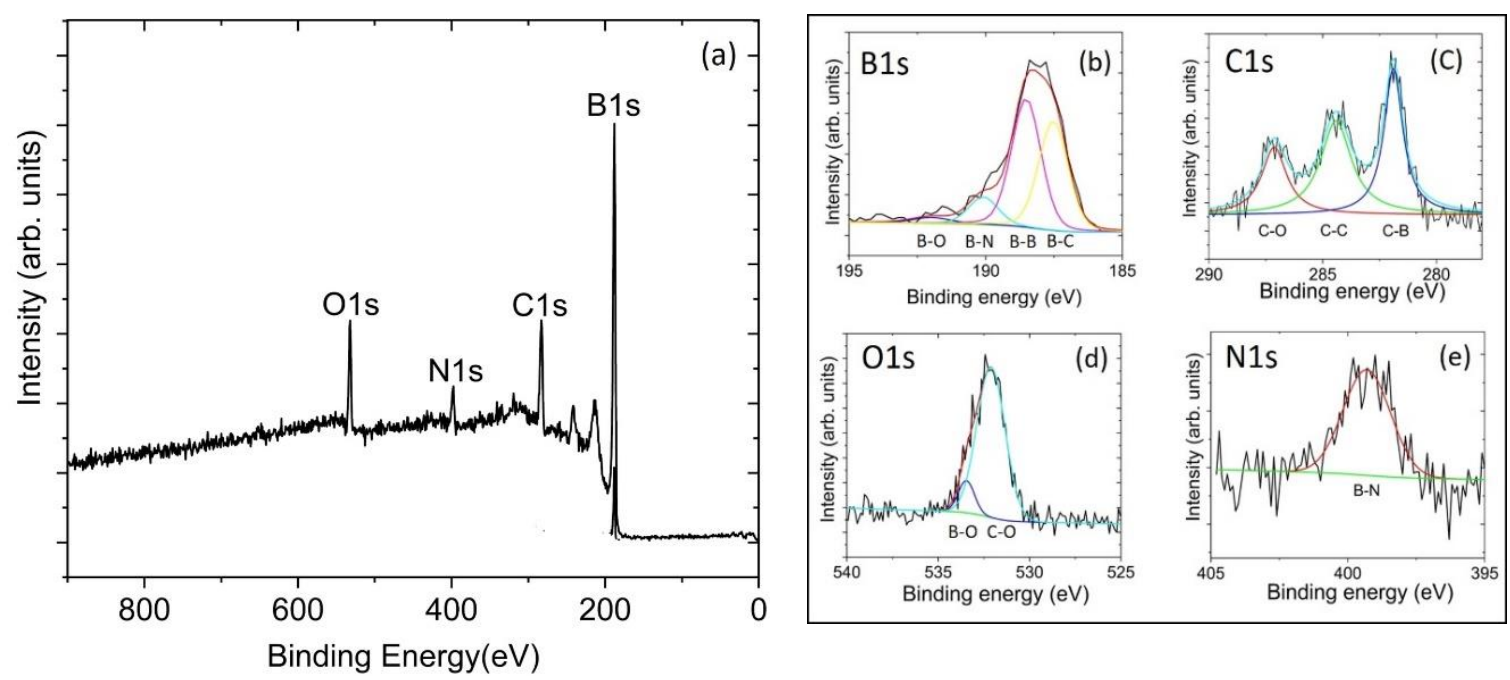

Figure 3. X-ray photoelectron spectroscopy survey scans of (a) the BC-2 coating with an elemental composition of $81.0 \%$ B, $12.6 \%$ C, $4.4 \%$ O, and $2.0 \%$ N. Panels (b-e) show high-resolution scans for B1s, $\mathrm{C} 1 \mathrm{~s}, \mathrm{O} 1 \mathrm{~s}$, and N1s, respectively, with corresponding peaks assigned to B-C, B-B, C-C (adventitious carbon), and C-O bonding. Sample BC-2 also shows bonding associated with B-N and B-O.

\subsection{X-ray Diffraction}

The crystal structure of the prepared coatings was evaluated using glancing angle $\mathrm{X}$-ray diffraction (XRD). Figure $4 \mathrm{a}, \mathrm{b}$ shows XRD patterns for BC-1 and BC-2, respectively. The BC-1 sample shows several broad peaks. The broadened peaks for the $\mathrm{BC}-1$ sample suggest a disordered or nanocrystalline nature for this boron carbide coating. The XRD pattern for the BC-2 sample shows sharp peaks located at the same positions as the centers of the broad peaks of the BC- 1 sample. The BC-2 sample also reveals a broad background superimposed onto the sharp peaks. Rietveld refinement was used to analyze the pattern for BC-2, as shown by the blue line in Figure $4 \mathrm{~b}$. The experimental pattern was matched to the stoichiometric composition of $\mathrm{B}_{25} \mathrm{C}$ with the chemical structure of $\mathrm{B}_{50} \mathrm{C}_{2}$ with lattice parameters $\mathrm{a}=8.721 \AA, \mathrm{c}=5.058 \AA$, as determined using HighScore Plus software, resulting in a weighted profile R-value (Rwp) of 10.248. It should be noted that existing XRD databases are not exhaustive for the wide range of boron-rich carbide structures (including those of $\mathrm{B}_{50} \mathrm{C}_{2}$ ) and several novel structures are still being reported experimentally or via computational approaches $[9,20,44]$. For this reason, the lattice constants determined from the performed Rietveld refinement are provided only for comparison with potential structures (e.g., tetragonal vs. orthorhombic $\mathrm{B}_{50} \mathrm{C}_{2}$ ) modeled by DFT calculations. 

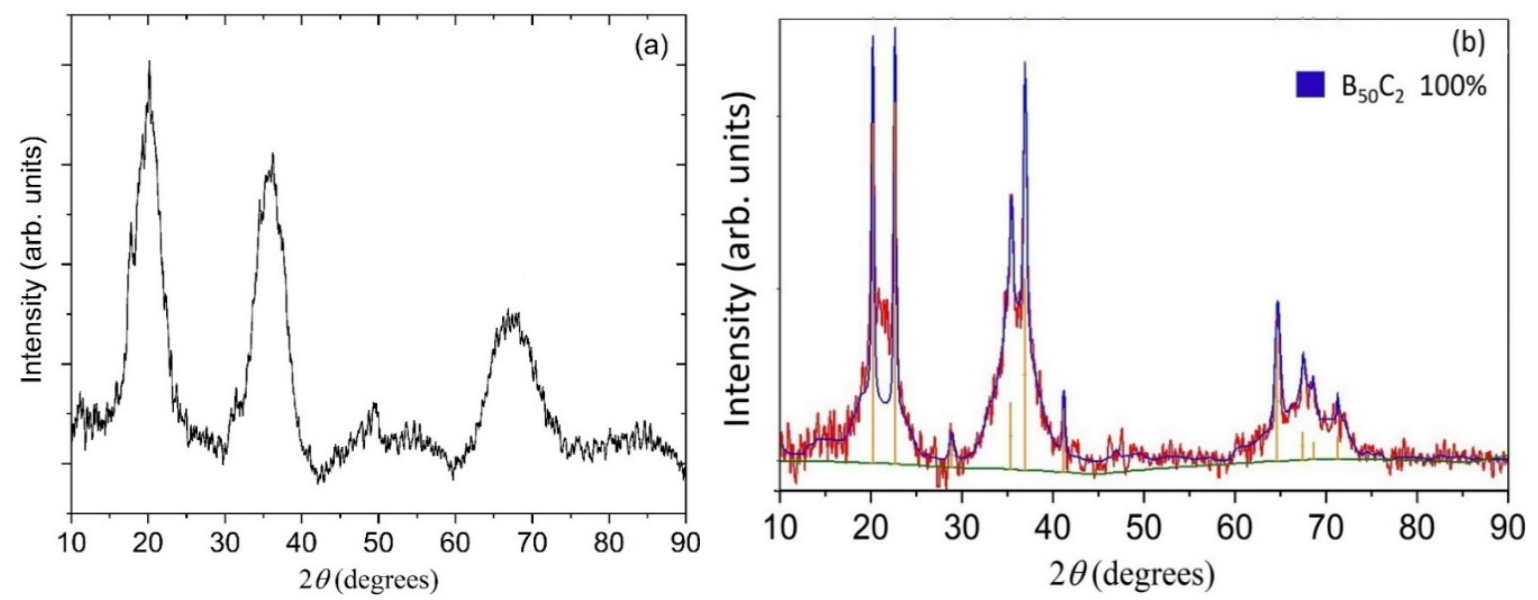

Figure 4. Glancing angle X-ray diffraction patterns for (a) sample BC-1 and (b) sample BC-2. The X-ray wavelength corresponds to $\mathrm{Cu} K-\alpha$ emission $(\lambda=1.54187 \AA)$. For $\mathrm{BC}-2$, the red curve is the raw data and the blue curve is the Rietveld refinement with lattice parameters $a=8.721 \AA$, $c=5.058 \AA$, and $\alpha=$ $\beta=\gamma=90^{\circ}$.

\subsection{Raman Spectroscopy}

Figure 5a shows the Raman spectra of sample BC-1. It is known that Raman-active lattice vibrations are affected much more by structural distortion than those of IR-active vibrations [45]. The spectrum of the BC-1 sample shows a combination of broad bands. The broad bands are typically more characteristic of an amorphous or a partially disordered structure. Figure $5 b$ shows the Raman spectra of the BC-2 sample, revealing two broad bands c.a. $1340 \mathrm{~cm}^{-1}$ and $1577 \mathrm{~cm}^{-1}$. These bands are commonly associated with disordered carbon and are often referred to as the " $\mathrm{D}$ " and " $\mathrm{G}$ " bands, respectively. These two bands indicate disordered $\mathrm{sp}^{2}$ - and $\mathrm{sp}^{3}$-bonded carbon in the $\mathrm{BC}-2$ sample and they have been reported in the literature for the deposition of boron carbide material $[7,16,21,46,47]$. The Raman spectrum of the BC-2 sample matches well with that found by Gao et al. in 2019 for $\mathrm{B}_{50} \mathrm{C}_{2}$ [7].
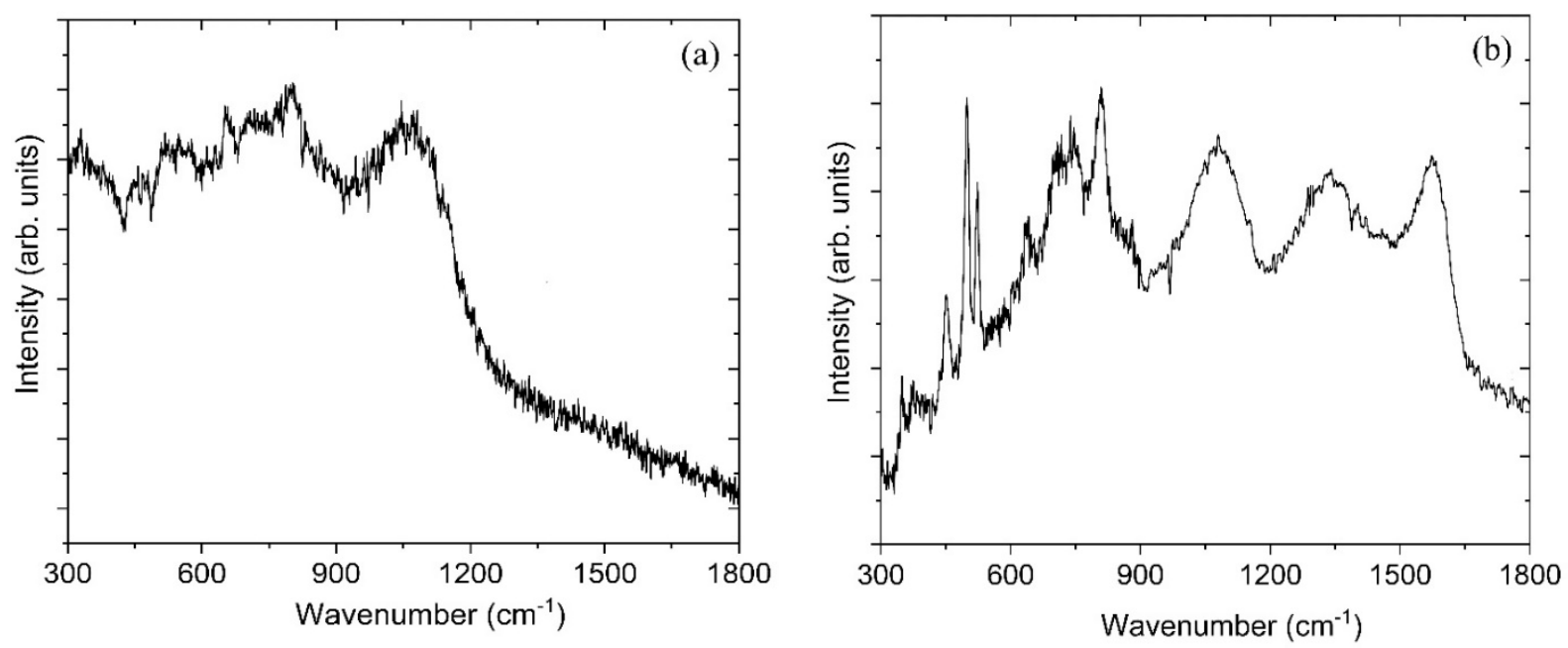

Figure 5. Raman spectra of (a) BC-1 and (b) BC-2 samples acquired in the range $300-1800 \mathrm{~cm}^{-1}$.

\subsection{Fourier Transform Infrared Spectroscopy (FTIR)}

To enable more insight into the nature of the chemical bonding present in the boron carbide coatings, FTIR spectral analysis was carried out, as shown in Figure 6. The complete peak assignment with transmittance frequency is also given in Tables 2 and 3 for BC- 1 and BC-2 respectively. 

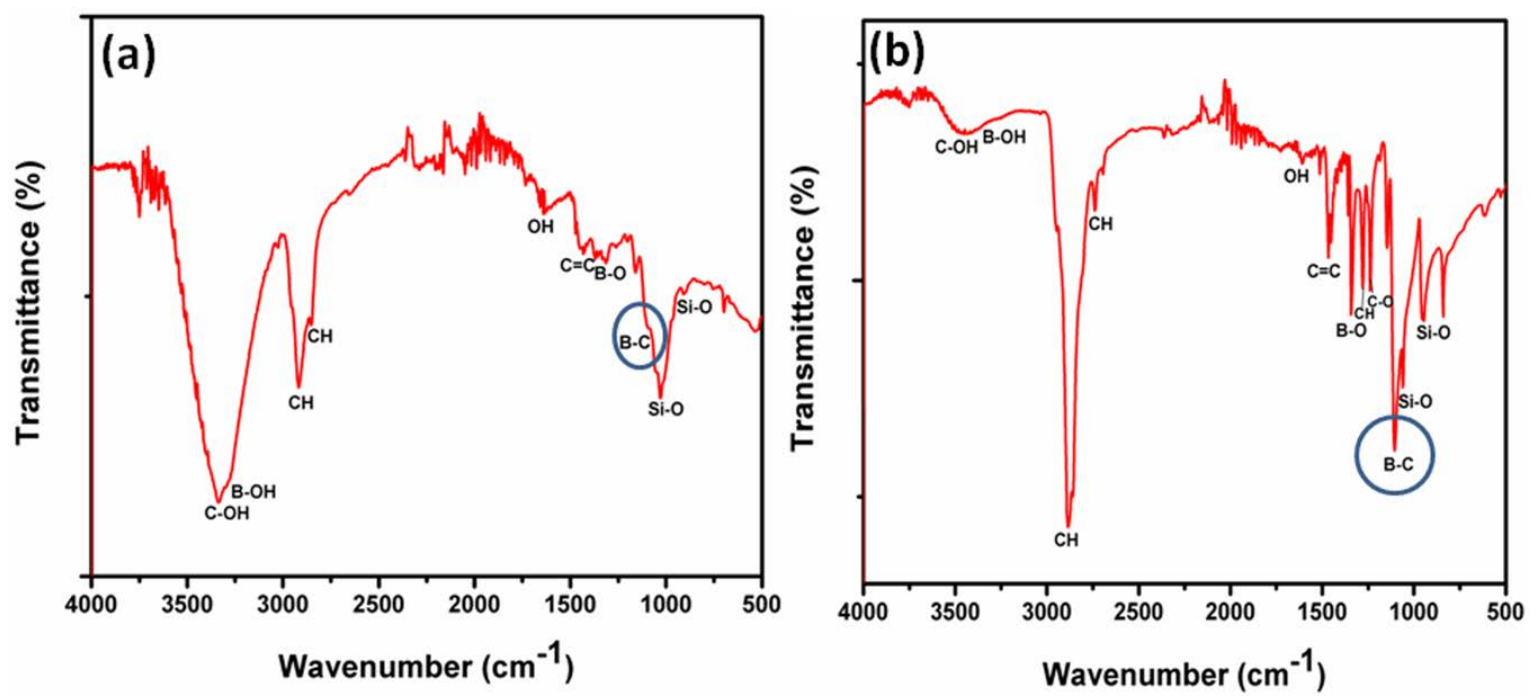

Figure 6. Fourier transformed infrared spectroscopy spectral analysis of the (a) BC-1 and (b) BC-2 samples.

Table 2. Complete peak assignment for the Fourier transformed infrared spectroscopy (FTIR) spectral analysis of the BC- 1 coating.

\begin{tabular}{|c|c|}
\hline Transmittance Frequency $\left(\mathrm{cm}^{-1}\right)$ & Assignment \\
\hline 1022 & Si-O stretching vibrations (from the silicon substrate) \\
\hline 1097 & B-C stretching vibrations \\
\hline 1305 & B-O stretching vibrations \\
\hline 1450 & $\mathrm{C}=\mathrm{C}$ stretching vibrations \\
\hline 1622 & $\mathrm{OH}$ bending modes of $\mathrm{C}-\mathrm{OH}$ and $\mathrm{B}-\mathrm{OH}$ groups \\
\hline 2857 & $\mathrm{CH}$ symmetric stretching vibrations \\
\hline 2910 & $\mathrm{CH}$ asymmetric stretching vibrations \\
\hline 3272 & B-OH stretching vibrations \\
\hline 3440 & $\mathrm{C}-\mathrm{OH}$ stretching vibrations \\
\hline
\end{tabular}

Table 3. Complete peak assignment for the FTIR spectral analysis of the BC-2 coating.

\begin{tabular}{cc}
\hline Transmittance Frequency $\mathbf{( \mathbf { c m } ^ { - \mathbf { 1 } } )}$ & Assignment \\
\hline 1058 & Si-O stretching vibrations (from the silicon substrate) \\
1107 & B-C stretching vibrations \\
1236 & C-O stretching vibrations \\
1340 & C-H bending vibrations \\
1450 & B-O stretching vibrations \\
1616 & C=C stretching vibrations \\
2750 & OH bending modes of C-OH and B-OH groups \\
2879 & CH symmetric stretching vibrations \\
3274 & CH asymmetric stretching vibrations \\
3442 & B-OH stretching vibrations \\
& C-OH stretching vibrations
\end{tabular}

The FTIR spectra of BC-1 and BC-2 exhibit several peaks in the fingerprint region $\left(1500-500 \mathrm{~cm}^{-1}\right)$. The major IR peaks of both BC-1 and BC-2 were assigned appropriately after cross-referencing with previously reported infrared studies of boron carbon chemical bonds $[18,48,49]$. Interestingly, BC-2 reveals more pronounced and sharper bands in comparison with BC-1. This can be attributed to the crystalline nature of the BC-2 coating (which may endow a more ordered arrangement of boron and carbon atoms) in comparison with the disordered nature of BC-1. The major peak of interest for both BC-1 and BC-2 is around $1100 \mathrm{~cm}^{-1}$ (more specifically 1097 and $1107 \mathrm{~cm}^{-1}$ for BC-1 and BC-2, 
respectively). The peak near $1100 \mathrm{~cm}^{-1}$ has been assigned to intra-icosahedral vibrations of the $\mathrm{B}-\mathrm{C}$ bond [50]. This major peak is sharper and more pronounced for BC-2 compared to BC-1. In addition to the boron-carbon bonding, there is the presence of other types of chemical bonds for both BC-1 and $\mathrm{BC}-2$, such as $\mathrm{C}-\mathrm{O}, \mathrm{C}=\mathrm{C}, \mathrm{C}-\mathrm{H}, \mathrm{B}-\mathrm{O}$, and $\mathrm{OH}$. The obtained peaks were found to be consistent with respect to the infrared spectrum of the boron-carbon bonds by Romanos et al. [49]. The peaks around $1022 \mathrm{~cm}^{-1}, 1058 \mathrm{~cm}^{-1}, 992 \mathrm{~cm}^{-1}$ (Si-O), and $700 \mathrm{~cm}^{-1}$ (Si-C) can be attributed to the contribution of the silicon substrate used to deposit the BC coating [51].

\subsection{Scanning Electron Microscopy (SEM)}

Scanning electron microscopy (SEM) was used to image the surface morphology of the BC-1 and BC-2 coating surfaces, as shown in Figure 7a,b, respectively. The surface morphology of these coatings is quite different. The BC-1 surface shows densely packed rounded nodules without any strong indication of crystalline facets. In contrast, the BC-2 coating shows large faceted platelets protruding from a very fine-grained base structure. There does not appear to be any preferred orientation of the crystalline facets and a few crystals appear to be twinned.
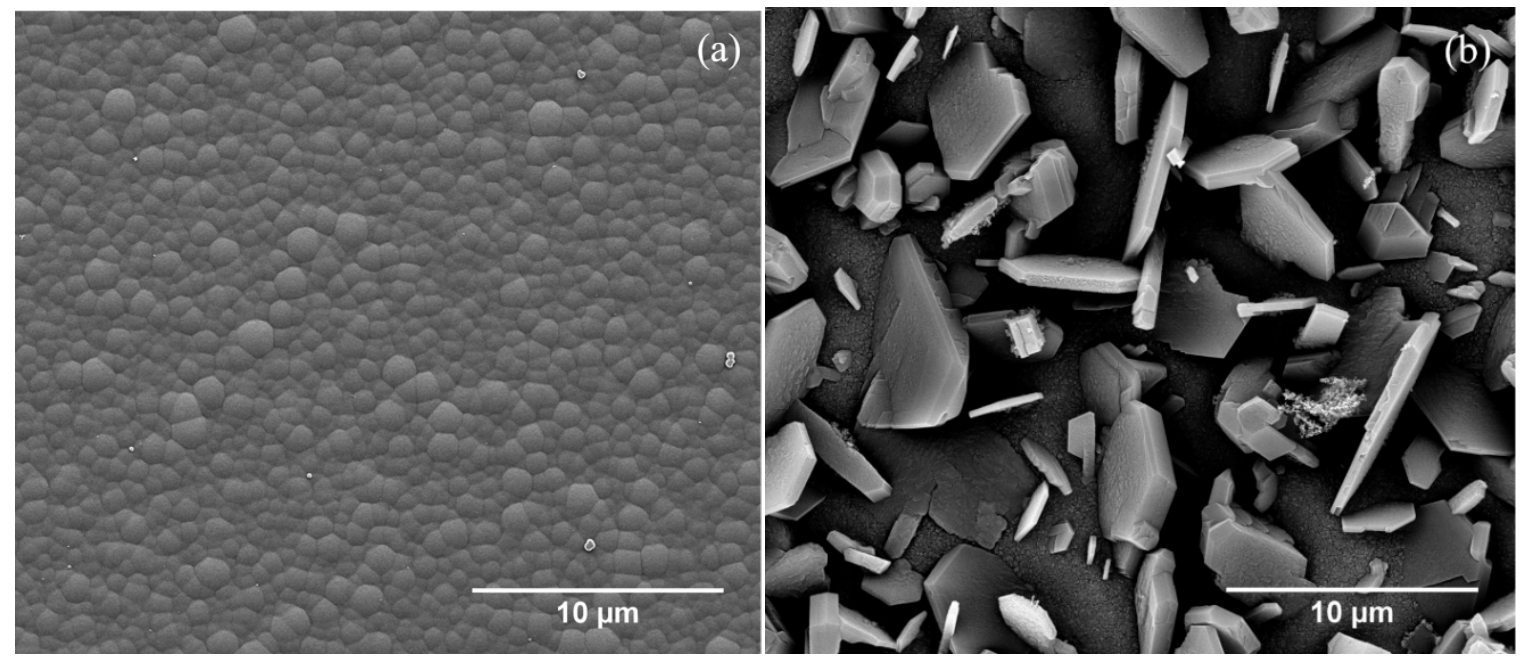

Figure 7. Scanning electron microscopy (SEM) images of samples (a) BC-1 and (b) BC-2. The much higher crystallinity of BC-2 is apparent from large facets with very fine-grained morphology between facets.

\subsection{Nanoindentation}

Figure 8 a shows the nanoindentation load/displacement data of sample BC- 1 . The indents were performed to a depth of $150 \mathrm{~nm}$ at several locations $(\mathrm{N}=11$ indents) on the film. The average hardness of all indents was $34 \mathrm{GPa}$ with several measurements greater than $40 \mathrm{GPa}$. The indent with the highest measured hardness was $64 \mathrm{GPa}$ and it had Young's modulus of $614 \mathrm{GPa}$. The average Young's modulus of this sample was $411 \mathrm{GPa}$. The relative contribution of elastic and plastic deformation can be calculated from the final unloading depth of the load-displacement curves. A high elastic recovery (about 67\%) from the boron carbide films was measured from the unloading data. Figure $8 \mathrm{~b}$ shows the large spread in the hardness data for sample BC-1. Factors which are likely to influence this spread include sample surface roughness and non-homogeneity in material properties at the scale of nanoindentation. Due to the much higher surface roughness of the crystalline sample (BC-2) and the corresponding difficulty in obtaining valid indented surface finds, this sample was not tested. 

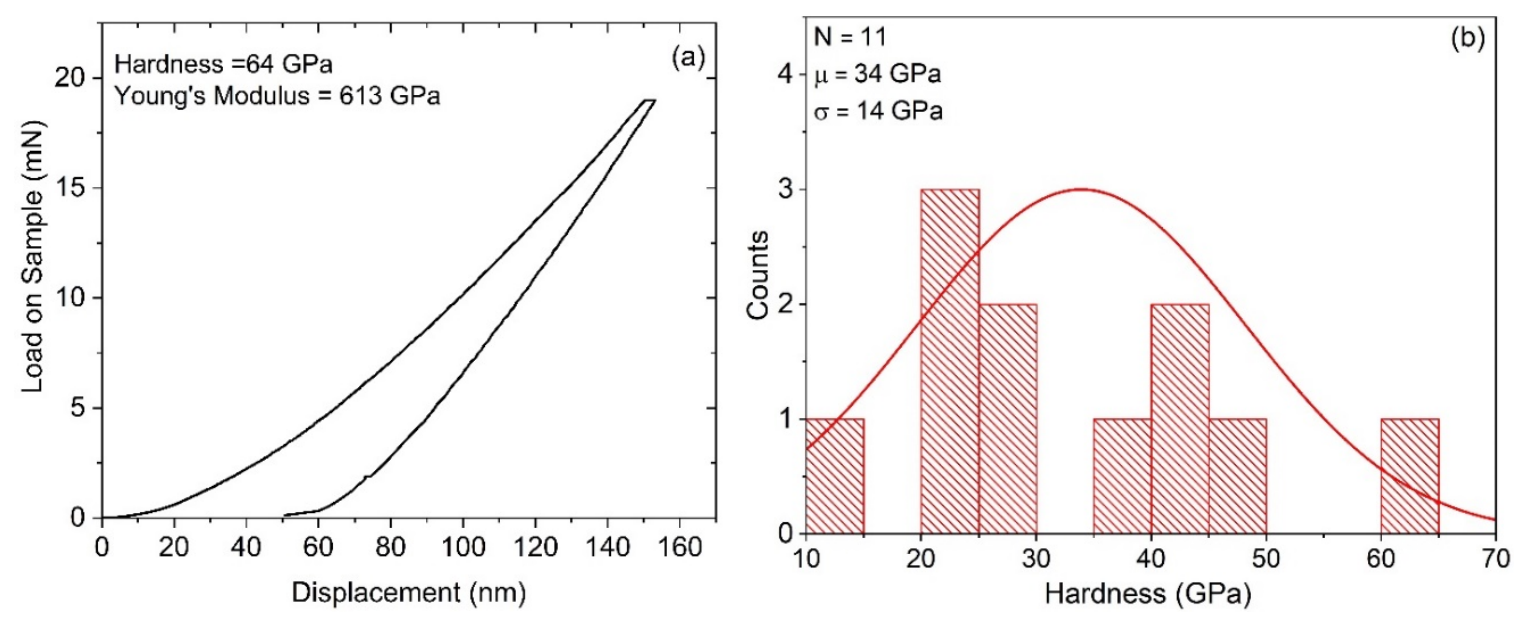

Figure 8. (a) Nanoindentation load-displacement curve from one location on the BC-1 coating at a depth of $150 \mathrm{~nm}$. The extracted values of nanoindentation hardness and Young's modulus are also indicated. (b) Histogram from 11 indents showing hardness values for sample BC-1.

\subsection{Density Functional Theory Calculations}

To better understand the crystalline sample BC-2, we first performed DFT calculations using $\mathrm{B}_{50} \mathrm{C}_{2}$ structures reported by Ploog et al. [52] and Will et al. [53] without structural relaxation, where two interstitial boron atoms are located at the Wyckoff $8 \mathrm{~h}$ or $8 \mathrm{i}$ sites, and two carbon atoms at the $2 \mathrm{~b}$ sites. Our phonon dispersion calculations for these structures have negative frequency modes (not shown). Even if the boron atoms are allowed to relax away from the high-symmetry Wyckoff $8 \mathrm{~h}$ or $8 \mathrm{i}$ positions, the negative modes still exist. These results indicate dynamical instability of these previously reported structures.

We next considered Will's $\mathrm{B}_{50} \mathrm{C}_{2}-8 \mathrm{i}$ (two borons at $8 \mathrm{i}$ ) and $\mathrm{B}_{50} \mathrm{C}_{2}-8 \mathrm{~h}$ (two borons at $8 \mathrm{~h}$ ) as initial structures, and then performed full structural relaxation calculations that allowed both unit cell and atomic positions to vary. Figure 9 a shows the structure of $B_{50} C_{2}-8 i^{\prime}$ (obtained by fully relaxing $B_{50} C_{2}-8 i$ ), which has the second lowest energy in our study (with a formation energy $=+3 \mathrm{meV} /$ atom compared to the $\mathrm{B}_{50} \mathrm{C}_{2}-8 \mathrm{~h}^{\prime}$ structure shown in Figure $\left.10 \mathrm{a}\right)$. In $\mathrm{B}_{50} \mathrm{C}_{2}-8 \mathrm{i}^{\prime}$, the two interstitial boron atoms relax from $8 \mathrm{i}(0.4334,0,0)$ to $8 \mathrm{i}^{\prime}(0.4395,-0.0019,-0.0091)$, and two carbon atoms from $2 \mathrm{~b}(0,0,0.5)$ to $2 \mathrm{~b}^{\prime}(0,0$, 0.4855). Based on the phonon spectra in Figure $9 b, B_{50} C_{2}-8 i^{\prime}$ is still dynamically unstable. In Figure $9 c$, we compare the theoretical $\mathrm{B}_{50} \mathrm{C}_{2}-8 \mathrm{i}^{\prime}$ and experimental $\mathrm{BC}-2$ sample XRD patterns. The main theoretical XRD peaks are in good agreement with the experiment. Figure $9 \mathrm{~d}$ shows the electronic density of states (DOS) for $\mathrm{B}_{50} \mathrm{C}_{2}-8 \mathrm{i}^{\prime}$, which is metallic with a finite DOS at the Fermi level. In our calculations, $\mathrm{B}_{50} \mathrm{C}_{2}-8 \mathrm{i}^{\prime}$ has bulk and shear moduli equal to 212 and $169 \mathrm{GPa}$, respectively. By means of Chen's empirical model [36], the Vickers hardness is found to be $28 \mathrm{GPa}$. We note that the relaxed $\mathrm{B}_{50} \mathrm{C}_{2}-8 \mathrm{i}^{\prime}$ structure remains tetragonal, which suggests that a dynamically stable structure might exist with a lower symmetry. 
(a)

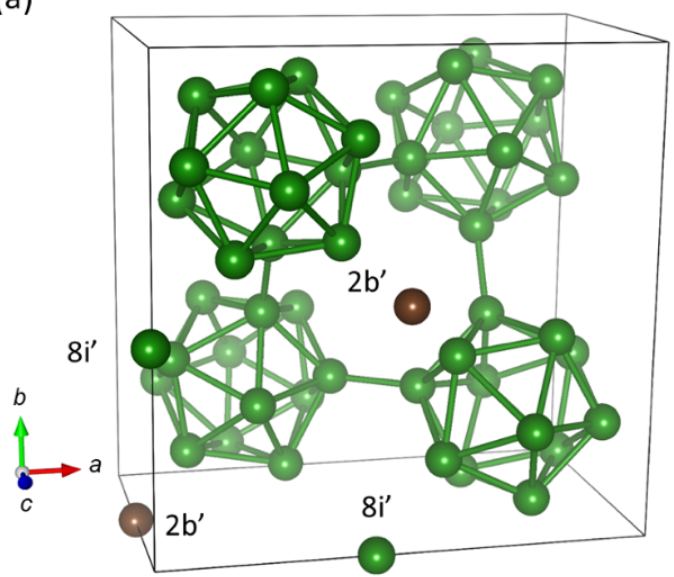

(c)

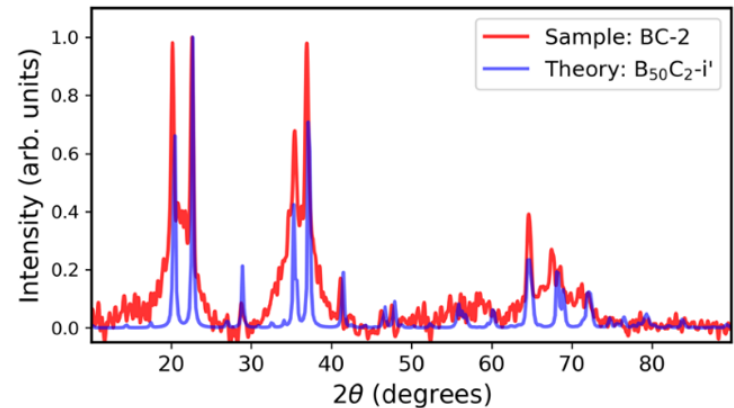

(b)

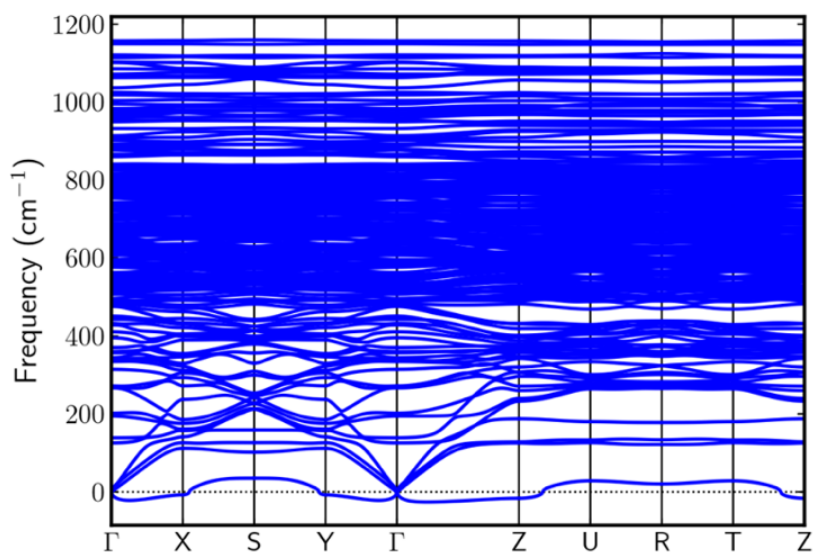

(d)

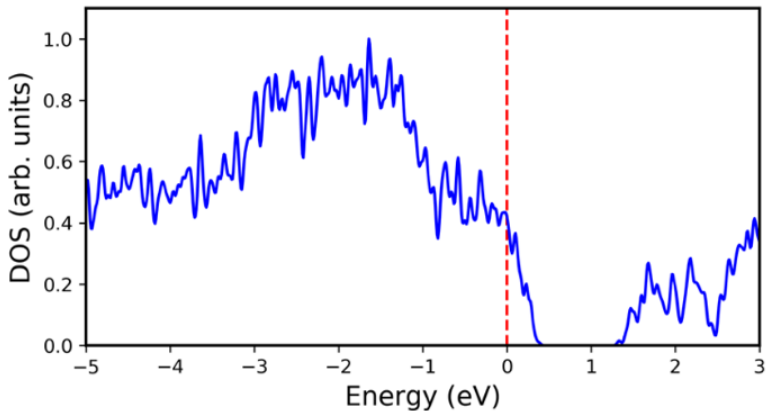

Figure 9. (a) The second lowest energy structure found in our density functional theory (DFT) calculations with full structure relaxation, B50C2-8i'. The tetragonal symmetry remains intact after relaxation. The positions of two carbon atoms move from $2 \mathrm{~b}(0,0,0.5)$ to $2 \mathrm{~b}^{\prime}(0,0,0.4855)$, and two boron atoms move slightly from $8 \mathrm{i}(0.4334,0,0)$ to $8 \mathrm{i}^{\prime}(0.4395,-0.0019,-0.0091)$. (b) Phonon dispersion of $\mathrm{B}_{50} \mathrm{C}_{2}-8 \mathrm{i}^{\prime}$ shows its dynamical instability. (c) Theoretical $\mathrm{B}_{50} \mathrm{C}_{2}-8 \mathrm{i}^{\prime} \mathrm{X}$-ray diffraction (XRD) pattern (blue) compared with experimental XRD pattern of the sample BC-2 (red). (d) Electronic calculations show finite DOS of $\mathrm{B}_{50} \mathrm{C}_{2}-8 \mathrm{i}^{\prime}$ at the Fermi level (red dashed line).

Figure 10a shows the structure of $\mathrm{B}_{50} \mathrm{C}_{2}-8 \mathrm{~h}$ ' (obtained by fully relaxing $\mathrm{B}_{50} \mathrm{C}_{2}-8 \mathrm{~h}$ ), which becomes orthorhombic with lattice parameters $\mathrm{a}=8.6772 \AA, \mathrm{b}=8.7237 \AA$, and $\mathrm{c}=5.0517 \AA$. This structure has the lowest energy in our study (with a formation energy $=0 \mathrm{meV} / \mathrm{atom}$ ). In $\mathrm{B}_{50} \mathrm{C}_{2}-8 \mathrm{~h}^{\prime}$, the two interstitial boron atoms relax from $8 \mathrm{~h}(0,0.5,0.8557)$ to $8 \mathrm{~h}^{\prime}(0,0.5,0.79588)$, and the two carbon atoms from $2 b(0,0,0.5)$ to $2 b^{\prime}(0,0,0.5033)$. Since no negative mode exists in the phonon dispersion in Figure $9 b, B_{50} C_{2}-8 h^{\prime}$ is dynamically stable. Figure 10 c compares the XRD patterns of the theoretical $\mathrm{B}_{50} \mathrm{C}_{2}-8 \mathrm{~h}^{\prime}$ structure and the $\mathrm{BC}-2$ sample, which also shows a good theory-experiment agreement. The DOS calculations for $\mathrm{B}_{50} \mathrm{C}_{2}-8 \mathrm{~h}^{\prime}$ in Figure 10d indicate its metallicity. The theoretical bulk and shear moduli, as well as Vickers hardness for $\mathrm{B}_{50} \mathrm{C}_{2}-8 \mathrm{~h}^{\prime}$, were computed to be $213 \mathrm{GPa}, 172 \mathrm{GPa}$, and $29 \mathrm{GPa}$, respectively. These values are similar to those for the $\mathrm{B}_{50} \mathrm{C}_{2}-8 \mathrm{i}^{\prime}$ structure in Figure $9 \mathrm{a}$. 
(a)

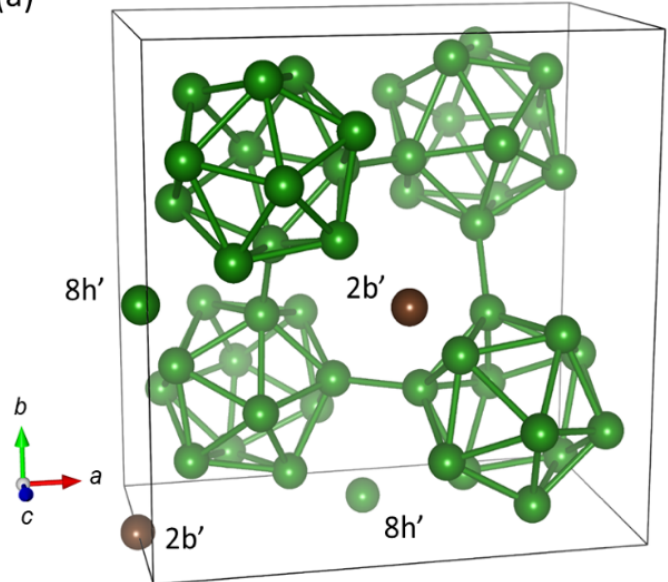

(c)

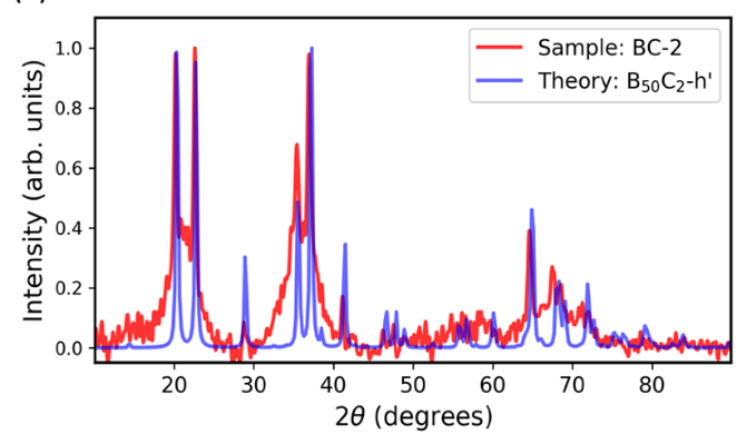

(b)

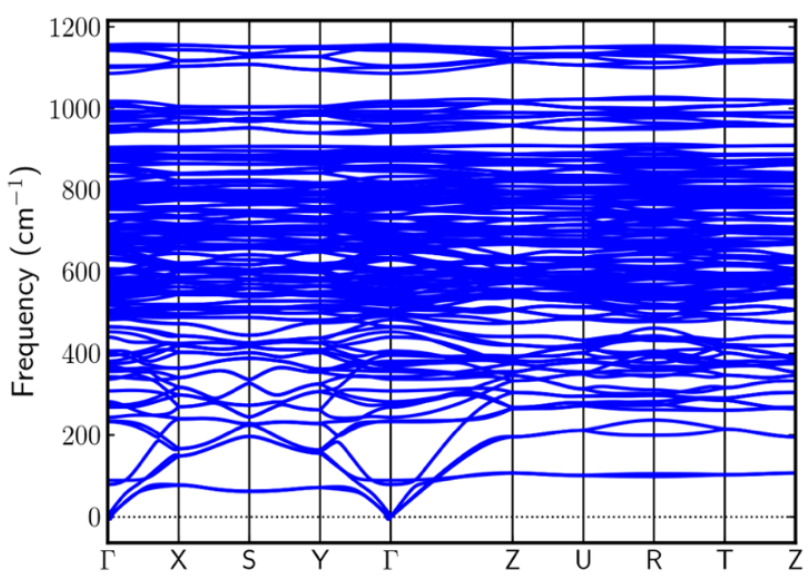

(d)

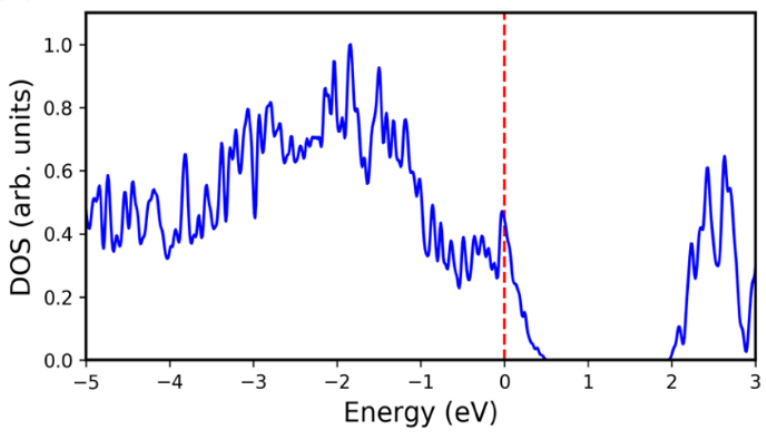

Figure 10. (a) The lowest energy structure found in our DFT calculations, $B_{50} C_{2}-8 h^{\prime}$. After full structure relaxation, the crystal symmetry changes from tetragonal to orthorhombic. The positions of the two carbon atoms move from $2 \mathrm{~b}(0,0,0.5)$ to $2 \mathrm{~b}^{\prime}(0,0,0.503)$, and the two boron atoms move from $8 \mathrm{~h}(0,0.5$, $0.8557)$ to $8 \mathrm{~h}^{\prime}(0,0.5,0.7908)$. (b) Phonon dispersion of relaxed $\mathrm{B}_{50} \mathrm{C}_{2}-8 \mathrm{~h}^{\prime}$ shows that it is dynamically stable. (c) Theoretical $\mathrm{B}_{50} \mathrm{C}_{2}-8 \mathrm{~h}^{\prime} \mathrm{XRD}$ pattern (blue) compared to the experimental XRD pattern of sample BC-2 (red). (d) Electronic calculations show finite DOS of B50C2-8h' at the Fermi level (red dashed line).

\section{Discussion}

The boron carbides exist as a single-phase material from about 8 at.\% carbon to about 20 at.\% carbon $[4,5]$. Very few studies have reported on the atomic structures of boron carbide in the regime below $\sim 13.3$ at.\% C (known as boron-very rich boron carbide, BvrBC) due to the complexity of the structure and bonding $[9,54]$. A model based on XRD data proposes that the 20 at. $\%$ carbon composition is made up of $B_{12}$ icosahedra and carbon-carbon-carbon (CCC) chains [55]. Other models also show that, at 20 at.\% carbon composition, a carbon atom is inserted into the icosahedra as $\mathrm{B}_{11} \mathrm{C}$ and can also make carbon-boron-carbon (CBC) chains [56,57]. As the atomic percentage of carbon decreases below $20 \%$ to around $13.3 \%$, boron preferentially replaces carbon in the icosahedron to form $\mathrm{B}_{12}$. Carbon atoms only remain in the icosahedral chain when their atomic percentage is around 13.3\% [6,58-60]. The atomic percentage of carbon is below $13.3 \%$ in our samples; and B-C bonded carbon is only $6.1 \%$ and $4.5 \%$ in BC-1 and BC-2, respectively. The atomic similarity between boron and carbon makes it difficult to distinguish their atomic locations in most characterization techniques. For boron carbides, Raman bands in the range of $600-1200 \mathrm{~cm}^{-1}$ correspond to vibrations involving icosahedral atoms. Two sharp peaks at $481 \mathrm{~cm}^{-1}$ and $534 \mathrm{~cm}^{-1}$ are assigned to vibrations related to the $C B C$ chain and a broad band centered at $400 \mathrm{~cm}^{-1}$ represents the CBB chain [4]. For the BC-1 sample, we observe two broad bands in the $600-1200 \mathrm{~cm}^{-1}$ range and no peaks that would correspond to the C-B-C or C-B-B chain formation. Instead, this sample shows broad peaks indicative of a disordered structure. 
Broadened peaks in the Raman spectra throughout the entire range investigated indicates disorder in the $B_{12}$ icosahedra. Such broadening can be due to structural defects, such as micro-twinning [22].

The BC-2 sample does show the two sharp Raman peaks around $481 \mathrm{~cm}^{-1}$ and $534 \mathrm{~cm}^{-1}$ associated with vibrations related to the CBC chain, along with broadened peaks throughout the entire wavenumber range. It is notable that the SEM of this sample shows microstructural twinning on crystalline facets as well as very fine-grained material between facets. This may explain the broad base to the peaks in the XRD data (Figure $4 \mathrm{~b}$ ). Different stoichiometric boron carbide structures, such as $\mathrm{B}_{4} \mathrm{C}$ and $\mathrm{B}_{50} \mathrm{C}_{2}$, result in distinctly different locations of boron atoms in the unit cell. Boron atoms in $\mathrm{B}_{4} \mathrm{C}$ belong to an icosahedron with a carbon chain in $\mathrm{B}_{4} \mathrm{C}$ or one boron atom in the icosahedron can be substituted by a carbon atom and form a C-B-C chain. In contrast, some of the boron atoms in $B_{50} C_{2}$ are in single atom form and take positions in interstitial sites, with carbon being isolated [7].

In the literature, two separate studies from Ploog et al. [52] and Will et al. [53] have reported two tetragonal structures with different lattice parameters. Ploog's structure has lattice parameters $a=b$ $=8.722 \AA$ and $c=5.080 \AA$, while Will's structure has $\mathrm{a}=\mathrm{b}=8.753 \AA$ and $\mathrm{c}=5.093 \AA$. In our DFT calculations, the phonon spectra of both structures show negative phonon modes, indicating their dynamical instabilities. In our calculations with fixed lattice parameters but relaxed Wyckoff positions, the boron atoms at $8 \mathrm{~h}(0,0.5, \mathrm{z})$ change dramatically from $\mathrm{z}=0.8557$ to $\mathrm{z}=0.7580$, while those at $8 \mathrm{i}$ $(x, 0,0)$ move only slightly from $x=0.4334$ to 0.4363 . However, these structures are still dynamically unstable even with relaxed Wyckoff positions.

In our subsequent DFT calculations that fully relax both lattice parameters and Wyckoff positions, the structure $B_{50} C_{2}-8 i^{\prime}$ (Figure 9a) remains in the tetragonal symmetry, with the lattice parameters change to $\mathrm{a}=\mathrm{b}=8.6906 \AA$ and $\mathrm{c}=5.0827 \AA$. The Wyckoff positions of two boron atoms move to $8 i^{\prime}(0.4395,-0.0019,-0.0091)$ and two carbon atoms to $2 b^{\prime}(0,0,0.4855)$. However, this fully relaxed tetragonal structure $\mathrm{B}_{50} \mathrm{C}_{2}-8 \mathrm{i}^{\prime}$ still shows negative phonon modes. In short, a tetragonal $\mathrm{B}_{50} \mathrm{C}_{2}$ appears dynamically unstable in DFT calculations.

On the other hand, for $\mathrm{B}_{50} \mathrm{C}_{2}-8 \mathrm{~h}^{\prime}$ (Figure 10a), the crystal symmetry changes to orthorhombic $(\mathrm{a}=8.6772 \AA, \mathrm{b}=8.7237 \AA, \mathrm{c}=5.0517 \AA)$, with the two boron atoms located at $8 \mathrm{~h}^{\prime}(0,0.5,0.79588)$ and two carbons at $2 b^{\prime}(0,0,0.5033)$. Importantly, this orthorhombic structure is dynamically stable. This $\mathrm{B}_{50} \mathrm{C}_{2}-8 \mathrm{~h}^{\prime}$ is also the most stable structure (formation energy $=0 \mathrm{meV} /$ atom) in DFT. Experimentally, an effective tetragonal phase might be observed due to a statistical average, as the two interstitial boron atoms could be randomly placed onto any two of the $8 \mathrm{~h}$ sites.

In our MPCVD system, we find that higher atomic boron and $\mathrm{BH}$ emissions were measured by optical emission spectroscopy (OES) at lower pressure and higher power. We used this fact in order to grow the boron-rich coatings in this study. In addition, subtle changes in the sample location within the plasma (determined by the molybdenum screw design, as shown in the inset of the Figure 1), which has a substantial effect on the shape of the plasma near the sample surface and on the corresponding coating structure. The control of the coatings' degree of crystallinity was achieved by manipulating the sample stage design (and thus the proximity of the sample to the plasma). Presumably, this affects the active growth species nearest the sample and allows for the control of the film structure. Future work will involve an investigation of spatially resolved optical emission spectroscopy to identify the spatial variation of excited state species near the growth surface. It is therefore very important to acknowledge and further investigate the strong influence that even very minor adjustments in sample proximity to the plasma have on the resulting film structure by MPCVD. Given that all other controlled deposition parameters were held fixed in this study (including substrate temperature to within $25^{\circ} \mathrm{C}$ ), we believe this allows a new parameter space to be carefully explored. In the current study, we have synthesized two boron-rich carbide structures yielding very different growth morphology and structural forms, with all other deposition parameters being equal. We plan to further take advantage of this parameter space that involves sample proximity to the plasma to create other unique superhard boron structures, such as $\mathrm{BC}_{2} \mathrm{~N}, \mathrm{~B}_{2} \mathrm{C}_{3} \mathrm{~N}, \mathrm{~B}_{4} \mathrm{C}_{5} \mathrm{~N}_{2}$, and $\mathrm{B}_{5} \mathrm{C}_{3} \mathrm{~N}$. 
In the studies of boron-rich materials, there exists a known discrepancy between experiment and theory, which was dubbed the metal/insulator problem by Uemura et al. [61]. Basically, band theory predicts several boron-rich materials like $\beta$-boron and $\mathrm{B}_{13} \mathrm{C}_{2}$ to be metallic. In experiments, however, these materials are found to be semiconductors [62]. This problem is related to the lack of ordering in interstitial atoms residing between $B_{12}$ icosahedra [61]. Such structures have been regarded as geometrically frustrated systems. In DFT, as long as the two carbon atoms are placed at the $2 \mathrm{~b}$ sites, $\mathrm{B}_{50} \mathrm{C}_{2}$ is metallic. One possible way to open an energy gap at the Fermi level is to insert one carbon into one of the four $B_{12}$ icosahedra [9]. Such metastable structures have formation energies around $15 \mathrm{meV} /$ atom above the ground state, which is still well below the thermal energy scale during synthesis $\left(825^{\circ} \mathrm{C} 100 \mathrm{meV} /\right.$ atom $)$. Therefore, from the viewpoint of thermodynamics, several different stable and metastable $\mathrm{B}_{50} \mathrm{C}_{2}$ phases could possibly exist to various extents during the chemical vapor deposition. However, resolving the metal/insulator problem is beyond the scope of our current research.

\section{Conclusions}

Superhard boron-rich carbide coatings were deposited in a microwave plasma chemical vapor deposition (MPCVD) system. The control of the coatings' degree of crystallinity was achieved by manipulating the sample stage design (and thus the proximity of the sample to the plasma). Amorphous boron-rich carbide coatings were grown on a flat sample holder, whereas crystalline boron-rich carbide coatings were formed on a sample holder with a shallow inset. XRD, Raman spectroscopy, and SEM were used to identify and characterize the amorphous or crystalline nature of boron-rich carbide coatings. Rietveld refinement of the crystalline sample led to the prediction of a $\mathrm{B}_{50} \mathrm{C}_{2}$-type structure. Hardness values of the amorphous sample are as high as $64 \mathrm{GPa}$. Nanoindentation measurements yield hardness values that vary considerably from point to point on the surface, so future work can focus on improving the homogeneity of the coatings. In our DFT calculations, tetragonal $\mathrm{B}_{50} \mathrm{C}_{2}$ structures were found to be dynamically unstable. The only dynamically stable structure, which is also the lowest energy structure, has an orthorhombic symmetry. In theory, unless carbon atoms are inserted directly into the $\mathrm{B}_{12}$ icosahedron, $\mathrm{B}_{50} \mathrm{C}_{2}$ crystalline phases are metallic. The ability to better control and understand the morphology, structure, and electronic property of $\mathrm{B}_{50} \mathrm{C}_{2}$ by microwave plasma chemical vapor deposition will enable further applications with superhard boron-rich boron carbide materials.

Author Contributions: Conceptualization, S.A.C.; formal analysis, K.C. and W.-C.C.; investigation, K.C., W.-C.C., P.A.B., and V.M.V.; methodology, K.C.; project administration, S.A.C.; software, W.-C.C. and C.-C.C.; supervision, C.-C.C. and S.A.C.; writing-original draft, K.C.; writing-review and editing, C.-C.C. and S.A.C. All authors have read and agreed to the published version of the manuscript.

Funding: This research was funded by the National Science Foundation (NSF) EPSCoR RII-Track-1 Cooperative Agreement OIA-1655280. Any opinions, findings, and conclusions or recommendations expressed in this material are those of the authors and do not necessarily reflect the views of the National Science Foundation.

Acknowledgments: The authors thank Bernabe Tucker for assistance with SEM measurements.

Conflicts of Interest: The authors declare no conflict of interest. The funders had no role in the design of the study; in the collection, analyses, or interpretation of data; in the writing of the manuscript, or in the decision to publish the results.

\section{References}

1. Hall, H.T.; Compton, L.A. Group IV Analogs and High Pressure, High Temperature Synthesis of $\mathrm{B}_{2} \mathrm{O}$. Inorg. Chem. 1965, 4, 1213-1216. [CrossRef]

2. Han, S.; Ihm, J.; Louie, S.G.; Cohen, M.L. Enhancement of Surface Hardness: Boron on Diamond (111). Phys. Rev. Lett. 1998, 80, 995-998. [CrossRef]

3. Velamakanni, A.; Ganesh, K.J.; Zhu, Y.; Ferreira, P.J.; Ruoff, R.S. Catalyst-Free Synthesis and Characterization of Metastable Boron Carbide Nanowires. Adv. Funct. Mater. 2009, 19, 3926-3933. [CrossRef]

4. Tallant, D.R.; Aselage, T.L.; Campbell, A.N.; Emin, D. Boron carbide structure by Raman spectroscopy. Phys. Rev. B 1989, 40, 5649-5656. [CrossRef] 
5. Bouchacourt, M.; Thevenot, F. The properties and structure of the boron carbide phase. J. Less Common Met. 1981, 82, 227-235. [CrossRef]

6. Saal, J.E.; Shang, S.; Liu, Z.-K. The structural evolution of boron carbide via ab initio calculations. Appl. Phys. Lett. 2007, 91, 231915. [CrossRef]

7. Gao, Y.; Ma, Y. Shear-Driven Chemical Decomposition of Boron Carbide. J. Phys. Chem. C 2019, 123, 23145-23150. [CrossRef]

8. Amberger, W.S.E.; Buschbec, B. Boron Compounds. In Gmelin Handbook of Inorganic Chemistry, 8th ed.; Springer: Berlin/Heidelberg, Germany, 1981.

9. Baker, P.A.; Chen, W.C.; Chen, C.C.; Catledge, S.A.; Vohra, Y.K. First-Principles Predictions and Synthesis of B50C2 by Chemical Vapor Deposition. Sci. Rep. 2020, 10, 4454. [CrossRef] [PubMed]

10. Beauvy, M. Stoichiometric limits of carbon-rich boron carbide phases. J. Less Common Met. 1983, 90, $169-175$. [CrossRef]

11. Shirai, K. Electronic structures and mechanical properties of boron and boron-rich crystals (Part I). J. Superhard Mater. 2010, 32, 205-225. [CrossRef]

12. Taylor, D.E.; McCauley, J.W.; Wright, T.W. The effects of stoichiometry on the mechanical properties of icosahedral boron carbide under loading. J. Phys. Condens. Matter 2012, 24, 505402. [CrossRef] [PubMed]

13. Golubeva, N.A.; Plyasunkova, L.A.; Kelina, I.Y.; Antonova, E.S.; Zhuravlev, A.A. Study of Reaction-Bonded Boron Carbide Properties. Refract. Ind. Ceram. 2015, 55, 414-418. [CrossRef]

14. Mukhanov, V.A.; Kurakevych, O.O.; Solozhenko, V.L. The interrelation between hardness and compressibility of substances and their structure and thermodynamic properties. J. Superhard Mater. 2008, 30, 368-378. [CrossRef]

15. Niihara, K.; Nakahira, A.; Hirai, T. The Effect of Stoichiometry on Mechanical Properties of Boron Carbide. J. Am. Ceram. Soc. 2006, 67, C-13-C-14. [CrossRef]

16. Domnich, V.; Reynaud, S.; Haber, R.A.; Chhowalla, M. Boron Carbide: Structure, Properties, and Stability under Stress. J. Am. Ceram. Soc. 2011, 94, 3605-3628. [CrossRef]

17. Gan, F. Structure and properties of amorphous thin film for optical data storage. J. Non-Cryst. Solids 2008, 354, 1089-1099. [CrossRef]

18. Hu, T.; Steihl, L.; Rafaniello, W.; Fawcett, T.; Hawn, D.D.; Mashall, J.G.; Rozeveld, S.J.; Putzig, C.L.; Blackson, J.H.; Cermignani, W.; et al. Structures and properties of disordered boron carbide coatings generated by magnetron sputtering. Thin Solid Film. 1998, 332, 80-86. [CrossRef]

19. Shirai, K. Electronic structures and mechanical properties of boron and boron-rich crystals (Part 2). J. Superhard Mater. 2010, 32, 336-345. [CrossRef]

20. Vast, N.; Sjakste, J.; Betranhandy, E. Boron carbides from first principles. J. Phys. Conf. Ser. 2009, 176. [CrossRef]

21. Gu, Y.; Chen, L.; Qian, Y.; Zhang, W.; Ma, J. Synthesis of Nanocrystalline Boron Carbide via a Solvothermal Reduction of $\mathrm{CCl}_{4}$ in the Presence of Amorphous Boron Powder. J. Am. Ceram. Soc. 2004, 88, 225-227. [CrossRef]

22. Thévenot, F. Boron carbide-A comprehensive review. J. Eur. Ceram. Soc. 1990, 6, 205-225. [CrossRef]

23. Jansson, U. Chemical Vapor Deposition of Boron Carbides. Mater. Manuf. Process. 1991, 6, 481-500. [CrossRef]

24. Sezer, A.O.; Brand, J.I. Chemical vapor deposition of boron carbide. Mater. Sci. Eng. B 2001, 79, 191-202. [CrossRef]

25. Chakrabarty, K.; Arnold, I.; Catledge, S.A. Hexagonal boron nitride grown using high atomic boron emission during microwave plasma chemical vapor deposition. J. Vac. Sci. Technol. A 2019, 37, 061507. [CrossRef]

26. Rau, A.; Chakrabarty, K.; Gullion, W.; Baker, P.A.; Bikmukhametov, I.; Martens, R.L.; Thompson, G.B.; Catledge, S.A. A diffusion approach for plasma synthesis of superhard tantalum borides. J. Mater. Res. 2019, 35, 481-490. [CrossRef]

27. Hohenberg, P.; Kohn, W. Inhomogeneous Electron Gas. Phys. Rev. 1964, 136, B864. [CrossRef]

28. Kohn, W.; Sham, L.J. Self-Consistent Equations Including Exchange and Correlation Effects. Phys. Rev. 1965, 140, A1133-A1138. [CrossRef]

29. Kresse, G.; Furthmüller, J. Efficiency of ab-initio total energy calculations for metals and semiconductors using a plane-wave basis set. Comput. Mater. Sci. 1996, 6, 15-50. [CrossRef] 
30. Kresse, G.; Furthmüller, J. Efficient iterative schemes for ab initio total-energy calculations using a plane-wave basis set. Phys. Rev. B 1996, 54, 11169-11186. [CrossRef]

31. Blöchl, P.E. Projector augmented-wave method. Phys. Rev. B 1994, 50, 17953. [CrossRef]

32. Kresse, G.; Joubert, D. From ultrasoft pseudopotentials to the projector augmented-wave method. Phys. Rev. B 1999, 59, 1758-1775. [CrossRef]

33. Perdew, J.P.; Burke, K.; Ernzerhof, M. Generalized Gradient Approximation Made Simple. Phys. Rev. Lett. 1996, 77, 3865-3868. [CrossRef] [PubMed]

34. Monkhorst, H.J.; Pack, J.D. Special points for Brillouin-zone integrations. Phys. Rev. B 1976, 13, 5188-5192. [CrossRef]

35. Togo, A.; Tanaka, I. First principles phonon calculations in materials science. Scr. Mater. 2015, 108, 1-5. [CrossRef]

36. Chen, X.-Q.; Niu, H.; Li, D.; Li, Y. Modeling hardness of polycrystalline materials and bulk metallic glasses. Intermetallics 2011, 19, 1275-1281. [CrossRef]

37. Momma, K.; Izumi, F. VESTA 3 for three-dimensional visualization of crystal, volumetric and morphology data. J. Appl. Crystallogr. 2011, 44, 1272-1276. [CrossRef]

38. Moulder, J.F. Handbook of X-ray Photoelectron Spectroscopy: A Reference Book of Standard Spectra for Identification and Interpretation of XPS Data; Physical Electronics Division, Perkin-Elmer Corporation: Waltham, MA, USA, 1992; p. 261.

39. Vincent, C.; Vincent, H.; Mourichoux, H.; Bouix, J. Characterization by XPS and SEM of reactive chemical vapour deposited boron carbide on carbon fibre. J. Mater. Sci. 1992, 27, 1892-1900. [CrossRef]

40. Al-Gaashani, R.; Najjar, A.; Zakaria, Y.; Mansour, S.; Atieh, M.A. XPS and structural studies of high quality graphene oxide and reduced graphene oxide prepared by different chemical oxidation methods. Ceram. Int. 2019, 45, 14439-14448. [CrossRef]

41. Kehrer, M.; Duchoslav, J.; Hinterreiter, A.; Cobet, M.; Mehic, A.; Stehrer, T.; Stifter, D. XPS investigation on the reactivity of surface imine groups with TFAA. Plasma Process. Polym. 2019, 16. [CrossRef]

42. Qu, J.; Li, Q.; Luo, C.; Cheng, J.; Hou, X. Characterization of Flake Boron Nitride Prepared from the Low Temperature Combustion Synthesized Precursor and Its Application for Dye Adsorption. Coatings 2018, 8, 214. [CrossRef]

43. Chen, L.; Goto, T.; Hirai, T.; Amano, T. State of boron in chemical vapour-deposited SiC-B composite powders. J. Mater. Sci. Lett. 1990, 9, 997-999. [CrossRef]

44. Kurakevych, O.O.; Solozhenko, V.L. Crystal structure of dense pseudo-cubic boron allotrope, pc-B52, by powder X-ray diffraction. J. Superhard Mater. 2013, 35, 60-63. [CrossRef]

45. Kuhlmann, U.; Werheit, H. Raman effect of boron carbide (B4.3C to B10.37C). J. Alloy. Compd. 1994, 205, 87-91. [CrossRef]

46. Erdemir, A.; Bindal, C.; Fenske, G.R. Formation of ultralow friction surface films on boron carbide. Appl. Phys. Lett. 1996, 68, 1637-1639. [CrossRef]

47. Domnich, V.; Gogotsi, Y.; Trenary, M.; Tanaka, T. Nanoindentation and Raman spectroscopy studies of boron carbide single crystals. Appl. Phys. Lett. 2002, 81, 3783-3785. [CrossRef]

48. Han, Z.; Li, G.; Tian, J.; Gu, M. Microstructure and mechanical properties of boron carbide thin films. Mater. Lett. 2002, 57, 899-903. [CrossRef]

49. Romanos, J.; Beckner, M.; Stalla, D.; Tekeei, A.; Suppes, G.; Jalisatgi, S.; Lee, M.; Hawthorne, F.; Robertson, J.D.; Firlej, L.; et al. Infrared study of boron-Carbon chemical bonds in boron-doped activated carbon. Carbon 2013, 54, 208-214. [CrossRef]

50. Pascual, E.; Martínez, E.; Esteve, J.; Lousa, A. Boron carbide thin films deposited by tuned-substrate RF magnetron sputtering. Diam. Relat. Mater. 1999, 8, 402-405. [CrossRef]

51. Philip, J.; Launer, B.A. Infrared Analysis of Organosilicon Compounds: Spectra-Structure Correlations. In Silicon Compounds: Silanes \& Silicones; Gelest, Inc.: Morrisville, PA, USA, 2013; pp. 175-178.

52. Ploog, K.; Schmidt, H.; Amberger, E.; Will, G.; Kossobutzki, K.H. B48B2C2 und B48B2N2, zwei Nichtmetallboride mit der Struktur des sog. I tetragonalen Bors. J. Less Common Met. 1972, 29, 161-169. [CrossRef]

53. Will, G.; Kossobutzki, K.H. X-ray diffraction analysis of B50C2 and B50N2 crystal-lizing in the "tetragonal" boron lattice. J. Less Common Met. 1976, 47, 33-38. [CrossRef] 
54. Yang, X.; Goddard, W.A.; An, Q. Structure and Properties of Boron-Very-Rich Boron Carbides: B12 Icosahedra Linked through Bent CBB Chains. J. Phys. Chem. C 2018, 122, 2448-2453. [CrossRef]

55. Clark, H.K.; Hoard, J.L. The Crystal Structure of Boron Carbide. J. Am. Chem. Soc. 1943, 65, $2115-2119$. [CrossRef]

56. Wood, C.; Emin, D. Conduction mechanism in boron carbide. Phys. Rev. B 1984, 29, 4582-4587. [CrossRef]

57. Van Schilfgaarde, M.; Harrison, W.A. Electronic structure of boron. J. Phys. Chem. Solids 1985, 46, $1093-1100$. [CrossRef]

58. Yakel, H.L. Recent developments in the structural crystallography of boron and the higher borides. Aip Conf. Proc. 1986, 140, 97-108. [CrossRef]

59. Larson, A.C. Comments concerning the crystal structure of $\mathrm{B}_{4}$ C. Aip Conf. Proc. 1986, 140, 5. [CrossRef]

60. Kirfel, A.; Gupta, A.; Will, G. The nature of the chemical bonding in boron carbide, B13C2. I. Structure refinement. Acta Crystallogr. Sect. B Struct. Crystallogr. Cryst. Chem. 1979, 35, 1052-1059. [CrossRef]

61. Uemura, N.; Shirai, K.; Eckert, H.; Kunstmann, J. Structure, nonstoichiometry, and geometrical frustration of $\alpha$-tetragonal boron. Phys. Rev. B 2016, 93, 104101. [CrossRef]

62. Schmechel, R.; Werheit, H. Correlation between structural defects and electronic properties of icosahedral boron-rich solids. J. Phys. Condens. Matter 1999, 11, 6803-6813. [CrossRef]

(C) 2020 by the authors. Licensee MDPI, Basel, Switzerland. This article is an open access article distributed under the terms and conditions of the Creative Commons Attribution (CC BY) license (http://creativecommons.org/licenses/by/4.0/). 